\title{
Therapeutic Implications of Monitoring End-tidal Carbon Dioxide in SubMassive Pulmonary Embolism
}

\author{
Sunil Kumar Garg, Pragya Garg \\ Department of Critical Care Medicine, NMC Hospital, Dubai, United Arab Emirates
}

\section{Abstract}

While managing submassive pulmonary embolism in Intensive Care Unit, it is always a challenge to identify the parameters to identify the deterioration. It is important to understand it as further therapeutic decision about the use of thrombolytics is based on its recognition. Bedside monitoring of end-tidal carbon dioxide which is readily available, continuous, noninvasive, and nonoperator dependent can be of help in deciding on the need of thrombolytics in such cases before development of hypotension.

Keywords: Alveolar dead space, end-tidal carbon dioxide, submassive pulmonary embolism, thrombolytics

\section{INTRODUCTION}

Submassive pulmonary embolism (PE) is defined as PE without systemic hypotension ( $\mathrm{SBP} \geq 90 \mathrm{~mm} \mathrm{Hg}$ ) but with either right ventricular dysfunction or myocardial necrosis. ${ }^{[1]}$ It accounts for about $20 \%$ of all PE. It has in-hospital mortality of about $2 \%-5 \%$ and significant morbidities such as chronic pulmonary hypertension, impaired quality of life, and recurrent venous thromboembolism. ${ }^{[2]}$ The evidence suggests that systemic thrombolytics can improve morbidity and may be mortality; however, this comes at the risk of increased major bleeding and intracranial haemorrhage $(2 \%-3 \%)$ when compared to anticoagulation alone. ${ }^{[2]}$

The American College of Chest Physicians recommendation for submassive PE advises thrombolytic therapy for select patients who are at low bleeding risk and whose initial clinical presentation or clinical course after starting anticoagulation suggests a high risk of developing hypotension. ${ }^{[3]}$

\section{Case Report}

A 24-year-old male presented with a history of shortness of breath of a few hours duration. His body mass index was $45 \mathrm{~kg} / \mathrm{m}^{2}$. He was a known diabetic but not taking any treatment. On clinical examination, heart rate was $86 / \mathrm{min}$, regular, blood pressure 140/86 $\mathrm{mm} \mathrm{Hg}$, respiratory rate $22 /$ min, and saturation on room air $95 \%$. His remaining clinical

\begin{tabular}{|l|l|}
\hline \multicolumn{2}{|c|}{ Access this article online } \\
\hline Quick Response Code: & Website: \\
& www.ijrconline.org \\
\cline { 2 - 2 } & \\
\hline
\end{tabular}

examination was normal. Findings on investigations included $\mathrm{S}_{1} \mathrm{Q}_{3} \mathrm{~T}_{3}$ pattern on electrocardiogram, normal chest $\mathrm{X}$-ray, and echocardiography revealed dilated right ventricle, pulmonary artery systolic pressure of $40 \mathrm{~mm} \mathrm{Hg}$, and normal left ventricle systolic function.

Computerized tomographic pulmonary angiography revealed the presence of large filling defect within the right and left pulmonary trunks extending to involve the segmental arteries on both sides partially sparing the right middle and left upper segmental and lower subsegmental arteries. His $\mathrm{N}$-terminal pro-B-type natriuretic peptide level was $966 \mathrm{pg} / \mathrm{ml}$, high-sensitive troponin $46 \mathrm{ng} / \mathrm{l}$, lactate $1.3 \mathrm{mmol} / \mathrm{L}$, and glycosylated hemoglobin $11 \%$.

After administering unfractionated heparin bolus in emergency, the patient was shifted to Intensive Care Unit on heparin infusion. He was asymptomatic in ICU and was maintaining blood pressure of 140/90 $\mathrm{mm} \mathrm{Hg}$. His end-tidal carbon dioxide $\left(\mathrm{EtCO}_{2}\right)$ value was $24 \mathrm{~mm} \mathrm{Hg}$ and arterial partial pressure of carbon dioxide $\left(\mathrm{PaCO}_{2}\right)$ was $43 \mathrm{~mm} \mathrm{Hg}$. While being monitored in Intensive Care Unit, his noninvasive blood pressure dropped to $96 \mathrm{~mm} \mathrm{Hg}$ systolic. At this point,

\section{Address for correspondence: Dr. Sunil Kumar Garg, NMC Hospital, Dubai, United Arab Emirates. E-mail: sucare12@yahoo.co.in}

This is an open access article distributed under the terms of the Creative Commons Attribution-NonCommercial-ShareAlike 3.0 License, which allows others to remix, tweak, and build upon the work non-commercially, as long as the author is credited and the new creations are licensed under the identical terms.

For reprints contact: reprints@medknow.com

How to cite this article: Garg SK, Garg P. Therapeutic implications of monitoring end-tidal carbon dioxide in submassive pulmonary embolism. Indian J Respir Care 2018;7:53-5. 
decision to thrombolyse was contemplated, and fluid bolus was given. His $\mathrm{EtCO}_{2}$ remained at the same value of $24 \mathrm{~mm} \mathrm{Hg}$ during this hemodynamic alteration, and the patient also remained asymptomatic. He was explained about possible thrombolysis, but he refused. Meanwhile, his next blood pressure reading after interval of $5 \mathrm{~min}$ again showed systolic blood pressure $>130 \mathrm{~mm} \mathrm{Hg}$.

The patient was actively involved in the decision-making process and finally consented to thrombolysis if blood pressure fell any further along with lowering of EtCO2 value. The heparin infusion was continued and partial thromboplastin time was monitored every $6 \mathrm{~h}$. Over a period of 2 days, the patient improved. His pulmonary artery systolic pressure reduced, $\mathrm{EtCO}_{2}$ increased to $32 \mathrm{~mm} \mathrm{Hg}$, and right ventricular dilatation decreased. He was discharged on $7^{\text {th }}$ day of admission on rivaroxaban.

\section{Discussion}

Systemic thrombolytics are given to patients with massive PE; however, the treatment of submassive PE is more challenging, and it is advised to evaluate their clinical course, comorbidities, and bleeding risk before administering thrombolytic therapy. ${ }^{[4]}$ Guidelines recommend thrombolytic therapy in select patients who deteriorate after starting anticoagulant therapy but have yet to develop hypotension and who have a low-bleeding risk over no such therapy.

While need of thrombolytics in submassive PE depends on deterioration, criteria to determine deterioration arenot defined. Development of hypotension in such patients will categorize them into massive $\mathrm{PE}$ and hence the candidate for thrombolytics. Guidelines do not mention or specify how to diagnose such deterioration before development of hypotension so that thrombolytic therapy can be initiated in a timely manner.

The onset of altered mentation or decrease in urine output in patients who are still holding blood pressure is less likely and is not objectively defined parameters. In addition, reliance on urinary output may lead to delay in recognition. Following up lactate levels appear to be more objective, but it is not a continuous real-time monitoring and needs repeated sampling. It can also be raised due to other reasons and does not identify increasing clot burden or decrease in cardiac output directly. Right ventricular size, systolic function, or pulmonary artery systolic pressure can be followed with echocardiography, but it may not always be readily available. Moreover, it is operator dependent and noncontinuous. Pulse oximetry appears to be more promising since it is readily available, real time, noninvasive, and commonly used modality of monitoring in hospital settings; however, the reliance on pulse oximetry and therefore peripheral perfusion in patients who have submassive PE cannot be relied on for therapeutic implications in isolation.

Most of the time such patients are on oxygen and to make interpretation of worsening hypoxia may be somewhat difficult. The obstruction of flow in embolized pulmonary arteries results in the creation of dead space in the corresponding regions of the lung. ${ }^{[5]}$ An increase in dead space has a direct effect on $\mathrm{EtCO}_{2}$.

In healthy adults, $\mathrm{EtCO}_{2}$ is lower than $\mathrm{PaCO}_{2}$ by $2-5 \mathrm{~mm} \mathrm{Hg}$. Alveoli with normal perfusion will have alveolar $\mathrm{CO}_{2}$ pressure almost equal to $\mathrm{PaCO}_{2}$ whereas alveoli with reduced/absent perfusion will have alveolar $\mathrm{CO}_{2}$ pressure equal to inhaled air pressure. End-tidal air is a mixture of gas from all alveoli, and hence, $\mathrm{EtCO}_{2}$ decreases to a degree that is commensurate with the extent of the dead space. ${ }^{[5]}$ As the alvelolar dead space volume increases, more $\mathrm{CO}_{2}$ free gas mixes in with gases from better-perfused units, thus lowering the $\mathrm{EtCO}_{2}$.

Any further fall in $\mathrm{EtCO}_{2}$ value over the baseline admission, value in submassive $\mathrm{PE}$ is a reflection of increasing alveolar dead space, and it can be contributed by increasing clot burden and/or further reduction in cardiac output secondary to the right ventricular systolic dysfunction and can be detected before the development of hypotension. Changeover of this dynamic condition from submassive toward massive can be detected earlier even before the development of hypotension by following the values of $\mathrm{EtCO}_{2}$. Moreover, it is simple, easily available, inexpensive, continuous, noninvasive, and nonoperator dependent method and reflects change in the underlying problem. Monitoring $\mathrm{EtCO}_{2}$ can thus be useful to decide on thrombolysis if $\mathrm{EtCO}_{2}$ further falls from baseline value at the time of admission. The rising $\mathrm{EtCO}_{2}$ value toward normal is a reflection of decreasing alveolar dead space and increasing perfusion hence response to the treatment.

The $\mathrm{EtCO}_{2}$ is affected by two other factors: production of carbon dioxide $\left(\mathrm{CO}_{2}\right)$ and minute ventilation. $\mathrm{CO}_{2}$ production is unlikely to change drastically in the usual setting of PE. However, many factors can change minute ventilation including pain, anxiety, and sedation, especially with opioids. It is important to note down the minute ventilation each time the $\mathrm{EtCO}_{2}$ is recorded. A sudden further decrease in $\mathrm{EtCO}_{2}$ without a change in minute ventilation can be used as an indicator of increase in dead space and hence worsening of submassive PE and possible need of thrombolytics.

Alternately, the arterial to $\mathrm{PaEtCO}_{2}$ can be used in conjunction with the absolute value of $\mathrm{EtCO}_{2}$. The arterial to $\mathrm{EtCO}_{2}$ difference can be measured in these patients at admission when the baseline blood gas analysis is obtained. They can then be monitored continuously and noninvasively with capnography. In the event of further sudden decrease in $\mathrm{EtCO}_{2}$, a blood gas analysis can be obtained. An increase in $\left(\mathrm{PaEtCO}_{2}\right)$ can be used as a confirmation of increase in dead space, in this case, due to further PE and help decide on thrombolysis.

\section{CONCLUSION}

All patients who are diagnosed as a case of submassive PE should be monitored with capnography. Any fall in $\mathrm{EtCO}_{2}$ value from baseline, in the absence of a significant change in minute ventilation, should be taken as worsening of underlying condition and as a guide to decide for thrombolysis before the 
development of overt hypotension. Similarly, any rise in its value from baseline indicates that the patient is improving. The arterial to $\mathrm{EtCO}_{2}$ difference can be used to confirm the increase in dead space. To better define its role, further studies are warranted.

\section{Declaration of patient consent}

The authors certify that they have obtained all appropriate patient consent forms. In the form the patient(s) has/have given his/her/their consent for his/her/their images and other clinical information to be reported in the journal. The patients understand that their names and initials will not be published and due efforts will be made to conceal their identity, but anonymity cannot be guaranteed.

\section{Financial support and sponsorship}

Nil.

\section{Conflicts of interest}

There are no conflicts of interest.

\section{REFERENCES}

1. Jaff MR, McMurtry MS, Archer SL, Cushman M, Goldenberg N, Goldhaber SZ, et al. Management of massive and submassive pulmonary embolism, iliofemoral deep vein thrombosis, and chronic thromboembolic pulmonary hypertension: A scientific statement from the American Heart Association. Circulation 2011;123:1788-830.

2. Treatment of Sub Massive Pulmonary Embolism: Full Dose, Half Dose or no Dose? Available from: http://www.rebelem.com/ treatment-of-submassive-pe-full-dose-half-dose-or-no-dose/. [Last accessed 2017 Aug 15].

3. Kearon C, Akl EA, Comerota AJ, Prandoni P, Bounameaux H, Goldhaber SZ, et al. Antithrombotic therapy for VTE disease: Antithrombotic therapy and prevention of thrombosis, $9^{\text {th }}$ ed: American College of Chest Physicians Evidence-Based Clinical Practice Guidelines. Chest 2012;141:e419S-96S.

4. Martin C, Sobolewski K, Bridgeman P, Boutsikaris D. Systemic thrombolysis for pulmonary embolism: A Review. P T 2016;41:770-5.

5. Schmidt GA. Pulmonic embolic disorders: Thrombus, air and fat. Principles of Critical Care. New York: McGraw-Hill; 1992. p. 1476-92. 